\title{
Effect of Single-liquid Priming Agents on Adhesive Bonding to Aluminum Oxide of a Methacrylic Resin
}

\author{
Kazuya YAMADA ${ }^{1}$, Hiroyasu KOIZUMI ${ }^{1,2}$, Yoshikazu KAWAMOTO ${ }^{1}$, Yumi ISHIKAWA ${ }^{1}$, Hideo \\ MATSUMURA ${ }^{1,2}$ and Naomi TANOUE ${ }^{3}$ \\ ${ }^{1}$ Department of Fixed Prosthodontics, Nihon University School of Dentistry, 1-8-13, Kanda-Surugadai, Chiyoda-ku, Tokyo \\ 101-8310, Japan \\ ${ }^{2}$ Division of Advanced Dental Treatment, Dental Research Center, Nihon University School of Dentistry, 1-8-13, Kanda- \\ Surugadai, Chiyoda-ku, Tokyo 101-8310, Japan \\ ${ }^{3}$ Department of Specialized Dentistry, Nagasaki University Hospital of Medicine and Dentistry, 1-7-1, Sakamoto, Nagasaki \\ 852-8501, Japan \\ Corresponding author, Hiroyasu KOIZUMI; E-mail: koizumi@dent.nihon-u.ac.jp
}

Received February 8, 2007/Accepted April 5, 2007

The purpose of this study was to evaluate the effects of acidic primers on adhesive bonding to sintered aluminum oxide (alumina). Alumina disks were primed with one of the following materials: Acryl Bond, All Bond 2 Primer B, Alloy Primer, Estenia Opaque Primer, Eye Sight Opaque Primer, M.L. Primer, MR. Bond, and Super-Bond Liquid. Specimens were then bonded with an acrylic resin initiated with partially oxidized tri- $n$-butylborane (TBBO), and bond strengths were determined. Unprimed specimen was employed as the control. Average bond strength before thermocycling ranged from 20.5 to 41.9 $\mathrm{MPa}$, whereas post-thermocycling bond strength ranged from 0.0 to $40.0 \mathrm{MPa}$. Of the eight primers, Estenia Opaque Primer and Alloy Primer showed better adhesive performance than the other materials. It could thus be concluded that either Estenia Opaque Primer or Alloy Primer - which contained an adhesive monomer, 10-methacryloyloxydecyl dihydrogen phosphate (MDP) - was recommended for bonding alumina with TBBO-initiated resin.

Keywords: Alumina, Primer, Partially oxidized tri- $n$-butylborane

\section{INTRODUCTION}

A growing number of ceramic restorative systems have been introduced for both anterior and posterior tooth-colored restorations. Aluminum oxide (i.e., alumina) has been used as a reinforcement component of dental porcelains ${ }^{1)}$. For example, high-purity alumina is being used as the prefabricated coping material of the Procera ceramic restorative system ${ }^{2}$. On the note about alumina-reinforced ceramic restorative systems, it is beneficial for both patients and clinicians alike that alumina or alumina-based copings and abutment teeth be strongly bonded for a longer service period of the restorations.

A number of reports have demonstrated the importance - and hence usefulness - of adhesive systems for bonding alumina ${ }^{3-14}$ and alumina-based ceramic materials ${ }^{15-17}$. For example, an adhesive resin that contained 4-methacryloyloxyethyl trimellitate anhydride (4-META) considerably enhanced bond strength to alumina ${ }^{3)}$. Similarly, silane monomers and/or surface preparations with silicon compounds were introduced for bonding alumina ceramic materials ${ }^{3.6,8-11,13,14}$. Besides, application of acidic compounds was also found to be effective for bonding alumina $^{3,6-14)}$.

To date, various acidic adhesive systems for bonding restorations and fixed partial dentures have been introduced ${ }^{18-21)}$. However, limited information is available concerning the bonding behavior of high- purity alumina, especially in relation to the chemical ingredients or functional monomers in the bonding agents $^{3)}$. The purpose of this study, therefore, was to evaluate the effects of acidic priming agents on the bond strength and durability of a tri- $n$-butylborane (TBB)-initiated resin bonded to high-purity alumina.

\section{MATERIALS AND METHODS}

\section{Materials used}

Alumina with $99.7 \%$ purity was sintered by the manufacturer at $1,600^{\circ} \mathrm{C}$ for five days and supplied as disk specimens. Two sizes of disk specimens (10 and $8 \mathrm{~mm}$ in diameter by $3 \mathrm{~mm}$ thickness) were used as adherend materials. Eight priming agents originally designed for conditioning casting alloys (Acryl Bond, AC; All Bond 2 Primer B, BP; Alloy Primer, AP; Estenia Opaque Primer, EP; Eye Sight Opaque Primer, EY; M.L. Primer, ML; MR. Bond, MR; and Super-Bond Liquid, SB) were assessed as adhesion promoters. All primers were single-liquid agents and contained at least one acidic functional monomer. A three-component, self-polymerizing methacrylic resin was selected as the luting agent. This resin consisted of an initiator, monomer liquid, and powder. The initiator was partially oxidized tri- $n$ butylborane (TBBO). The monomer liquid was methyl methacrylate (MMA). The powder was finely pulverized poly(methyl methacrylate) (PMMA; SuperBond $\mathrm{C} \& \mathrm{~B}$ Opaque Ivory powder). Information on 
Table 1 Materials assessed

\begin{tabular}{|c|c|c|c|c|}
\hline Material & Abbreviation & Manufacturer & Lot number & Composition (\%) \\
\hline \multicolumn{5}{|l|}{ Adherend material } \\
\hline Sintered alumina & & Furuuchi Chemical Corp., Tokyo, Japan & & $99.7 \mathrm{Al}_{2} \mathrm{O}_{3}, 0.08 \mathrm{SiO}_{2}, 0.05 \mathrm{Mg}$ \\
\hline \multicolumn{5}{|l|}{ Primer } \\
\hline Acryl Bond & $\mathrm{AC}$ & Shofu Inc., Kyoto, Japan & 050322 & 4-AETA, 2-HEMA, MMA \\
\hline All Bond 2 Primer B & B P & Bisco Inc., Schaumburg, IL, USA & 0500002159 & BPDM \\
\hline Alloy Primer & AP & Kuraray Medical Inc., Tokyo, Japan & 00195A & MDP, VBATDT, Acetone \\
\hline Estenia Opaque Primer & $\mathrm{E} P$ & Kuraray Medical Inc., Tokyo, Japan & 00130A & MDP, Solvent \\
\hline Eye Sight Opaque Primer & E Y & Kanebo Corp., Tokyo, Japan & $\mathrm{R} 37$ & MP, Solvent \\
\hline M.L. Primer & ML & Shofu Inc., Kyoto, Japan & 040302 & 10-MDDT, 6-MHPA, Acetone \\
\hline MR. Bond & MR & Tokuyama Dental Corp., Tokyo, Japan & 013 & MAC-10, MMA \\
\hline Super-Bond Liquid & S B & Sun Medical Co. Ltd., Moriyama, Japan & GG5 & 4-META, MMA \\
\hline
\end{tabular}

Luting agent

Super-Bond Catalyst

Methyl methacryla te

Super-Bond Opaque Powder
MMA
GR71

FGK01
Partially oxidized tri- $n$-butylborane (TBBO)

99.8 MMA

PolyMMA (PMMA), $\mathrm{TiO}_{2}$

4-AETA: 4-acryloyloxyethyl trimellitate anhydride; 2-HEMA: 2-hydroxyethyl methacrylate; BPDM: Adduct of 2-HEMA and 3,4,4',-̄'-biphenyl tetracarboxylic anhydride; MDP: 10-methacryloyloxydecyl dihydrogen phosphate; VBATDT: 6-(4-vinylbenzyl- $n$-propyl)a mino-1,3,5-triazine-2,4dithione; MP: Methacrylate-phosphate; 10-MDDT: 10-methacryloyloxydecyl 6,8-dithiooctanoate; 6-MHPA: 6-methacryloyloxyhexyl phosphonoacetate; MAC-10: 11-methacryloyloxy-1,1-undecane dicarboxylic acid; 4-META: 4-methacryloyloxyethyl trimellitate anhydride.

the materials is summarized in Table 1 .

\section{Specimen preparation}

A total of 144 pairs of disk specimens were wetground with 1,500-grit silicon carbide abrasive paper, and ultrasonically cleaned with acetone. The 144 disk pairs were divided into nine sets (eight primers and unprimed control) of 16 specimen pairs. A piece of tape with a hole $5 \mathrm{~mm}$ in diameter and $50 \mu \mathrm{m}$ in thickness was positioned on the surface of the 10mm-diameter alumina specimen to define the bond area and thickness of the luting agent. Except for the control specimens (16 pairs), 128 pairs of the specimens were primed with one of the eight primers and air-dried. The 8- and $10-\mathrm{mm}$ disks were bonded with the resin material using brush-dip technique. After bonding, a $5.0 \mathrm{~N}$ load was applied to the specimens until setting of the luting material. Thickness of the resin material was approximately $55 \mu \mathrm{m}$.

Thermocycling and shear bond strength measurement After 30 minutes, the bonded specimens were immersed in water at $37^{\circ} \mathrm{C}$ for 24 hours. This state was defined as 0 thermocycles, and half of the specimens (nine sets of eight pairs) were tested at this stage. The remaining half of the specimens (nine sets of eight pairs) were subsequently thermocycled in water between $5^{\circ} \mathrm{C}$ and $55^{\circ} \mathrm{C}$ for 100,000 cycles with a 60-second dwell time per bath (Thermal Shock Tester TTS-1 LM, Thomas Kagaku Co. Ltd., Tokyo, Japan). Each specimen was positioned in a steel mold and seated in a shear testing jig (ISO TR $11405)^{222}$. Shear bond strength was determined by means of a mechanical testing device (Type 5567, Instron Corp., Canton, MA, USA) at a crosshead speed of $0.5 \mathrm{~mm} / \mathrm{min}$. Average shear bond strength and standard deviation of eight replications were calculated for each group.

\section{Statistical analysis}

The results were primarily analyzed by Kruskal Wallis test (SPSS ver. 14.0J, SPSS Inc., Chicago, IL, USA), followed by Steel - Dwass test (KyPlot 4.0, KyensLab Inc., Tokyo, Japan) with the value of statistical significance set at 0.05 . Difference between the pre- and post-thermocycling bond strengths within an identical priming condition was analyzed with Mann-Whitney U test (SPSS ver. 14.0J) at $a=0.05$ level.

\section{Failure analysis}

After shear testing, the debonded surfaces were observed by means of an optical microscope (SZX9, Olympus Corp., Tokyo, Japan) at $\times 8$ magnification. Failure modes were classified into the following three 
categories: Adhesive failure at the luting agentalumina interface (A); Cohesive failure within the luting agent $(\mathrm{C})$; and combination of cohesive and adhesive failures (CA).

\section{RESULTS}

Results of shear testing are summarized in Table 2. Average pre-thermocycling bond strength ranged from 20.5 to $41.9 \mathrm{MPa}$. Among the prethermocycling groups, unprimed control group showed significantly lower bond strength (category a) than the other eight groups (category b). Bond strengths before application of thermocycling of the eight primed groups $(37.2-41.9 \mathrm{MPa})$ were not statistically different from each other (category b).

Post-thermocycling bond strengths ranged from 0.0 to $40.0 \mathrm{MPa}$, and they were categorized into seven categories from category c through category i. Unprimed control group again showed the lowest bond strength (category c), followed by the group primed with All Bond 2 Primer B (category d). Each of the categories e, $f$, and $g$ encompassed three groups, and their bond strengths gradually changed from 15.0 $\mathrm{MPa}$ to $30.3 \mathrm{MPa}$. Greatest postthermocycling bond strengths (category i) were achieved in the two groups primed with either Estenia Opaque Primer or Alloy Primer.

Mann - Whitney U test revealed that the bond strengths of these two groups (Estenia Opaque Primer and Alloy Primer) were not significantly reduced by thermocycling $(p=0.130$ and 0.645), whereas the bond strengths of the other seven groups were significantly reduced $(\mathrm{p}<0.001)$.

Types of bond failure observed through an optical microscope are summarized in Table 3.

Table 2 Median, mean, and standard deviation values of shear bond strength in $\mathrm{MPa}$

\begin{tabular}{|c|c|c|c|c|c|c|c|c|c|c|c|c|c|c|c|c|}
\hline \multicolumn{6}{|c|}{0 thermocycles } & \multicolumn{3}{|c|}{ 100,000 thermocycles } & & & & & & & & \multirow[b]{2}{*}{$\mathrm{p}$-value } \\
\hline Primer & Median & Mean & $\mathrm{SD}$ & & & Median & Mean & $\mathrm{SD}$ & & & & & & & & \\
\hline UP & 18.6 & 20.5 & 5.8 & $\mathrm{a}$ & & 0.0 & 0.0 & 0.0 & c & & & & & & & $\mathrm{p}<0.000^{*}$ \\
\hline B P & 37.3 & 37.2 & 2.7 & & $\mathrm{~b}$ & 1.6 & 2.2 & 1.3 & & d & & & & & & $\mathrm{p}<0.000^{*}$ \\
\hline $\mathrm{AC}$ & 38.4 & 38.4 & 1.8 & & $\mathrm{~b}$ & 18.0 & 15.0 & 5.7 & & & e & & & & & $\mathrm{p}<0.000^{*}$ \\
\hline E Y & 39.3 & 39.4 & 2.4 & & $b$ & 17.5 & 18.7 & 4.9 & & & e & f & & & & $\mathrm{p}<0.000^{*}$ \\
\hline S B & 39.6 & 39.8 & 2.9 & & $\mathrm{~b}$ & 24.6 & 25.8 & 4.8 & & & e & f & g & & & $\mathrm{p}<0.000^{*}$ \\
\hline $\mathrm{ML}$ & 39.4 & 39.5 & 3.0 & & b & 29.0 & 28.0 & 3.6 & & & & f & $g$ & & & $\mathrm{p}<0.000^{*}$ \\
\hline MR & 38.7 & 37.9 & 2.2 & & $\mathrm{~b}$ & 29.9 & 30.3 & 3.2 & & & & & g & $\mathrm{h}$ & & $\mathrm{p}<0.000^{*}$ \\
\hline $\mathrm{AP}$ & 41.9 & 41.9 & 1.9 & & b & 39.6 & 39.2 & 3.7 & & & & & & $\mathrm{~h}$ & i & $\mathrm{p}=0.130$ \\
\hline EP & 40.8 & 41.0 & 3.4 & & $\mathrm{~b}$ & 39.7 & 40.0 & 1.8 & & & & & & & $\mathrm{i}$ & $\mathrm{p}=0.645$ \\
\hline
\end{tabular}

SD: Standard deviation.

Identical letters indicate that values are not significantly different ( $p>0.05)$. Statistical analysis method was Steel _ Dwass test.

*: Significant difference between pre- and post-thermocycling bond strengths $(\mathrm{p}<0.05)$. Statistical analysis method was Mann - Whitney U test.

Table 3 Failure modes after shear bond testing

\begin{tabular}{|c|c|c|c|c|c|c|}
\hline \multirow[t]{2}{*}{ Primer } & \multicolumn{3}{|c|}{0 thermocycles } & \multicolumn{3}{|c|}{100,000 ther mocycles } \\
\hline & A & CA & $\mathrm{C}$ & A & $\mathrm{CA}$ & $\mathrm{C}$ \\
\hline $\mathrm{UP}$ & 8 & 0 & 0 & 8 & 0 & 0 \\
\hline B P & 8 & 0 & 0 & 8 & 0 & 0 \\
\hline $\mathrm{AC}$ & 8 & 0 & 0 & 8 & 0 & 0 \\
\hline EY & 8 & 0 & 0 & 8 & 0 & 0 \\
\hline S B & 8 & 0 & 0 & 8 & 0 & 0 \\
\hline ML & 7 & 1 & 0 & 8 & 0 & 0 \\
\hline MR & 8 & 0 & 0 & 8 & 0 & 0 \\
\hline $\mathrm{AP}$ & 6 & 1 & 1 & 8 & 0 & 0 \\
\hline E P & 2 & 4 & 2 & 8 & 0 & 0 \\
\hline
\end{tabular}

A: Adhesive failure at the aluminum oxide interface; C: Cohesive failure within the luting agent; CA: Combination of adhesive and cohesive failures. 
Reduction in cohesive failure and increase in adhesive failure were observed for majority of the groups after thermocycling. As for the unprimed control specimens, they showed adhesive failure both before and after thermocycling.

\section{DISCUSSION}

This study evaluated the adhesive characteristics of sintered alumina using single-liquid primers and a self-polymerizing methacrylic resin. Alumina adherends were used without surface preparation which is intended to provide positive mechanical retention - for two key reasons. The first reason was that the purpose of the current study was to singularly evaluate the effect of functional monomers in chemical bonding, rather than the effect of mechanical retention - although the system employed is currently inapplicable to clinical settings. The other reason was that surface preparation for mechanical retention was difficult for alumina, because alumina is resistant to acid attack.

This study used a TBBO-initiated resin as the luting agent. The resin did not contain any adhesive functional monomer in the composition. This composition made it possible to singularly evaluate the effect of functional monomers in the primers. If Super-Bond adhesive were used in the current study, the effect of varying acidic functional monomers could not be evaluated because the monomer liquid of the Super-Bond resin contained 4-META monomer.

As shown in the results, the use of either Alloy Primer or Estenia Opaque Primer demonstrated the highest post-thermocycling bond strengths. These results probably arose from a difference in bonding ability between the MDP monomer and other acidic monomers. In a previous report ${ }^{23)}$, dental porcelain, silicon oxide, and alumina adherends were separately bonded with a TBBO-initiated resin using either carboxylic monomers or a silane monomer. The results showed that carboxylic monomers rather than a silane monomer were effective for bonding alumina. Similarly, other studies demonstrated the effectiveness of MDP monomer in bonding dental base metal alloys and base metals $\mathrm{s}^{19-21,24-26)}$. Both base metal alloys and alumina are usually covered with a metal oxide layer. As MDP was found to be effective for bonding base metals or metal oxides, it was thus consistent that the present experimental result showed that the MDP monomer was useful for bonding alumina, because alumina is an oxide of aluminum metal.

Between the two phosphate monomers, i.e., hydrophobic MDP and hydrophilic methacrylate phosphate (MP), the former demonstrated better bond durability to base metal alloys than the latter $^{1926)}$. These previous findings ${ }^{19,26)}$ also agreed with the current result that MDP was superior to MP as an adhesion promoter for alumina. The authors speculated that penetration of water to resin-alloy bonded interface was considerably prevented by the presence of a hydrophobic decyl group, which was just adjacent to the divalent phosphate structure. Taken together, the previous findings and the results of the current study supported the speculation that the hydrophobic MDP monomer was superior to other acidic monomers for bonding specific metal oxides including alumina.

Sen et $a l^{16)}$ reported that the MDP-based Panavia composite showed higher bond strength than the Super-Bond acrylic resin for bonding In-Ceram glass-infiltrated porous alumina cores. At least three factors were at play to account for the difference between the Panavia composite and the Super-Bond resin: matrix system, initiator, and functional monomer. In the current experiment, both the luting resin and the initiator were combined into one entity. As for remaining factor of functional monomer, it was evaluated using eight priming agents. As shown in the results, the MDP monomer exhibited the best performance. This result hence supported the hypothesis that the MDP monomer was the best compound for priming alumina, within the limitations of the current experimental setting.

Analysis of debonded surfaces (Table 3) showed different distributions of failure modes between pre- and post-thermocycled specimens primed with Estenia Opaque Primer. The authors speculated that monomer conversion of resin material was still progressing and on the increase at the prethermocycling stage. Hence, mechanical strength of the adhesive layer was not maximal at this stage. Integrity of bonded interface, however, was considerably high because the specimen was not so much attacked by the penetration of water into the interface. These factors may enhance probability of combined debonding of adhesive and cohesive failures.

Based on the results obtained, it seemed that the mechanical strength of thermocycled resin materials might be stronger than that of nonthermocycled materials. However, adherend-resin interface integrity of thermocycled specimens was lower than that of non-thermocycled specimens. These factors thus accounted for the increased adhesive failures at the adherend-resin interface. Indeed, pre- and post-thermocycled specimens primed with Estenia Opaque Primer demonstrated different failure modes before and after application of thermal stress, although calculated bond strengths were comparable.

Given the correlation between functional monomer and adherend composition, it is thus important for clinicians to select and employ a compatible 
bonding system. In conclusion, it could be said that the use of either Estenia Opaque Primer or Alloy Primer - which contained an adhesive monomer, MDP - was recommended for bonding sintered alumina with TBBO-initiated methacrylic resin.

\section{ACKNOWLEDGEMENTS}

This work was supported in part by a Grant-in-Aid for Young Scientists (B) (No. 18791455) from the Ministry of Education, Culture, Sports, Science and Technology of Japan (MEXT, Japan), Special Research Grants for the Development of Distinctive Education from the Promotion and Mutual Aid Corporation for Private School of Japan (2006), Grant from Dental Research Center, Sato Fund, Nihon University School of Dentistry, and Nihon University Research Grant for Assistants and Young Researchers (2006).

\section{REFERENCES}

1) McLean JW, Hughes TH. The reinforcement of dental porcelain with ceramic oxides. Br Dent J 1965; 119: 251-267.

2) Andersson M, Oden A. A new all-ceramic crown. A dense-sintered, high-purity alumina coping with porcelain. Acta Odontol Scand 1993; 51: 59-64.

3) Matsumura H, Nakamura M, Nakabayashi N, Tanaka T, Atsuta M. Effect of a silane coupling agent and ferric chloride on the bonding of porcelain, quartz and alumina with 4-META/MMA-TBB resin. Dent Mater J 1987; 6: 135-139.

4) Awliya W, Oden A, Yaman P, Dennison JB, Razzoog ME. Shear bond strength of a resin cement to densely sintered high-purity alumina with various surface conditions. Acta Odontol Scand 1998; 56: 9 13.

5) Blixt M, Adamczak E, Linden LA, Oden A, Arvidson K. Bonding to densely sintered alumina surfaces: effect of sandblasting and silica coating on shear bond strength of luting cements. Int $\mathrm{J}$ Prosthodont 2000; 13: 221-226.

6) Friederich R, Kern M. Resin bond strength to densely sintered alumina ceramic. Int $\mathrm{J}$ Prosthodont 2002; 15: 333-338.

7) Blatz MB, Sadan A, Arch GH Jr, Lang BR. In vitro evaluation of long-term bonding of Procera AllCeram alumina restorations with a modified resin luting agent. J Prosthet Dent 2003; 89: 381-387.

8) Blatz MB, Sadan A, Blatz U. The effect of silica coating on the resin bond to the intaglio surface of Procera AllCeram restorations. Quintessence Int 2003; 34: 542-547.

9) Blatz MB, Sadan A, Soignet D, Blatz U, Mercante D, Chiche G. Long-term resin bond to densely sintered aluminum oxide ceramic. J Esthet Restor Dent 2003; 15: 362-368.

10) Sadan A, Blatz MB, Soignet D. Influence of silanization on early bond strength to sandblasted densely sintered alumina. Quintessence Int 2003; 34: 172-176.
11) Hummel M, Kern M. Durability of the resin bond strength to the alumina ceramic Procera. Dent Mater 2004; 20: 498-508.

12) Piwowarczyk A, Lauer HC, Sorensen JA. In vitro shear bond strength of cementing agents to fixed prosthodontic restorative materials. J Prosthet Dent 2004; 92: 265-273.

13) Valandro LF, Della Bona A, Antonio Bottino M, Neisser MP. The effect of ceramic surface treatment on bonding to densely sintered alumina ceramic. J Prosthet Dent 2005; 93: 253-259.

14) Valandro LF, Ozcan M, Bottino MC, Bottino MA, Scotti R, Bona AD. Bond strength of a resin cement to high-alumina and zirconia-reinforced ceramics: the effect of surface conditioning. J Adhes Dent 2006; 8: 175-181.

15) Kern M, Thompson VP. Bonding to glass infiltrated alumina ceramic: adhesive methods and their durability. J Prosthet Dent 1995; 73: 240-249.

16) Sen D, Poyrazoglu E, Tuncelli B, Goller G. Shear bond strength of resin luting cement to glassinfiltrated porous aluminum oxide cores. J Prosthet Dent 2000; 83: 210-215.

17) Komine F, Tomic M, Gerds T, Strub JR. Influence of different adhesive resin cements on the fracture strength of aluminum oxide ceramic posterior crowns. J Prosthet Dent 2004; 92: 359-364.

18) Ide T, Tanoue N, Yanagida H, Atsuta M, Matsumura $\mathrm{H}$. Effectiveness of bonding systems on bonding durability of a prefabricated porcelain material. Dent Mater J 2005; 24: 257-260.

19) Ishikawa $Y$, Kawamoto $Y$, Nemoto M, Koizumi H, Nemoto K, Matsumura H. Effect of acidic primers on bonding three magnetic steel alloys with tri- $n$ butylborane initiated methacrylic resin. Dent Mater J 2005; 24: 642-647.

20) Tsuchimoto Y, Yoshida Y, Mine A, Nakamura M, Nishiyama N, Van Meerbeek B, Suzuki K, Kuboki T. Effect of 4-MET- and 10-MDP-based primers on resin bonding to titanium. Dent Mater J 2006; 25: 120-124.

21) Koizumi H, Furuchi M, Tanoue N, Yanagida H, Yoneyama T, Matsumura H. Bond strength to primed Ti-6Al-7Nb alloy of two acrylic resin adhesives. Dent Mater J 2006; 25:286-290.

22) International Organization for Standardization. Dental materials - Guidance on testing of adhesion to tooth structure. ISO TR 11405, 1994.

23) Matsumura H, Tanaka T, Atsuta M, Nakamura M, Nakabayashi N. Bonding of porcelain, quartz and alumina with a silane coupling agent and carboxylic monomers. J Jpn Prosthodont Soc 1987; 31: 14941498.

24) Matsumura H, Tanaka T, Taira $Y$, Atsuta M. Bonding of a cobalt-chromium alloy with acidic primers and tri- $n$-butylborane-initiated luting agents. J Prosthet Dent 1996; 76: 194-199.

25) Suzuki M, Yamamoto M, Fujishima A, Miyazaki T, Hisamitsu H, Kojima K, Kadoma Y. Raman and IR studies on adsorption behavior of adhesive monomers in a metal primer for $\mathrm{Au}, \mathrm{Ag}, \mathrm{Cu}$, and $\mathrm{Cr}$ surfaces. J Biomed Mater Res 2002; 62: 37-45.

26) Yanagida H, Matsumura H, Atsuta M. Bonding of prosthetic composite material to Ti-6Al-7Nb alloy with eight metal conditioners and a surface modification technique. Am J Dent 2001; 14: 291-294. 